\title{
What Do They Eat? A Survey of Eat-Out Habit of University Students in Taiwan
}

\begin{abstract}
Kuang-Yu Shih ${ }^{a}$, Ming-Yuan Wang ${ }^{a}$, Hsueh-Chieh Shih ${ }^{b}$, S.Y. Lee ${ }^{c}$, Ta-Yu Lin ${ }^{d^{*}}$
${ }^{a}$ Department of tourism management, National Kaohsiung University of Science and Technology, Kaohsiung, Taiwan, email: shiguangyufb@gmail.com. ${ }^{\mathrm{b}}$ Department of hotel and M.I.C.E. management, Overseas Chinese University, Taichung, Taiwan, email:kitty@ocu.edu.tw. ${ }^{c}$ Department of food and beverage management, University of Kang Ning, Tainan, Taiwan, email:freedom@ukn.edu.tw. ${ }^{\mathrm{d}}$ Department of Leisure Management, University of Kang Ning, Tainan, Taiwan, email:jeremy@ukn.edu.tw.
\end{abstract}

\begin{abstract}
Main purpose of this research is trying to understand food likeliness of Taiwan college students, and probe whether these food are healthy. Three survey steps are taken as: step 1, market survey for what kind of foods are selling around the campuses; step 2, questionnaire investigation for students food preference; step 3, analyzing whether these favorite foods are healthy or not. The result shows: major consideration for students food selection are "taste" and "price"; 63\% of students are taking food or snacks late at night at least once a week. Top three most favorite foods are: Taiwanese fries (yan su ji), carbon grilled chicken and fried fish steaks. Quantities of these foods are small, prices are low, and easy access from roadside food stands. Problems of them are high calories, easy to accumulate free radical in human body, plus insanitary food processing environment. They are harmful to student health. We suggest Taiwan government take it seriously.
\end{abstract}

Keywords: College student, diet healthiness, food safety, food nutrition.

*Author for correspondence: Tel:+886-975635718; E-mail: jeremy@ukn.edu.tw 


\section{Introduction}

Convenient and fast are two major incentives for people to bring to-go food to work place or school (Lee, 2013); Yet, unhealthy eating behavior and custom will make serious adverse result for people's health. Recent researches indicated that the trend of people getting cardiovascular and chronic diseases are getting younger (Chen and Yan, 2015), cardiovascular disease is no more a problem of senior people (Liu and Yang, 2010). In the long run, it is easy to cause problems of uneven nutritious taking and higher risks in getting obese and high blood pressure, blood fat and blood sugar (Luo et al., 2012). Hence, modern consumers are thinking highly on food safety and nutrition.

In addition to traditional cafeteria, lots of snacks, fried, iced and other instant foods are emerging in college campuses. Although they provide variable selections and solve students' diet needs, they are temptation for unbalanced diet. Meanwhile, lots of businessman are aiming college students and setting up food processing and stands within 100 campus meters (Zhou, 2010). These snacks are seducing students, making them sick if ate unhygienic food. Research reveals that most students are unaware importance of diet (Su and Fan, 2016). Eat casually, like to buy from food stands, and drive by convenience (Shen et al., 2015). More than $70 \%$ of college students taking custom or taste as their choice (Li, 2018). Therefore, healthy diet should be an important issue. Understanding their eating preference and custom are important to their eating activities and health.

Up to this date, there are limited papers on the health issue around Taiwan college campuses food stands and shops, and their relations with college students diet habit and health. Most papers are focusing on students self-conscience health, health idea, and diet activities (Chen and Yen, 2015); college students food knowledge and diet activities (Luo et al., 2018); or educate college students hygiene knowledge and skills (Chih et al., 2016). Little researches are on their diet habit and foods around them. Consequently,purpose of this research is investigating Taiwan college students diet preferences and habits, then analyzing their consumption patterns and healthiness.

\section{Theoretical Analysis}

Research shows, nutritious knowledge has positive correlation with diet activity. Nutritious knowledge influences diet activity. Diet activity has profound influences on health. Unhealthful diet activities will increase probabilities for getting chronic diseases and obsesses (Chen et al., 2016). Unfortunately, most college students are not pay attention to 
health issue (Luo et al., 2017), Li (2013) indicates: college students often taking fried food and late night snacks while watching TV or reading books. They are not eating in a regular manner, unbalanced nutritious taking, loving high calorie food, and high ratios of eating late night snacks (Hang et al., 2009), taking irregular diet habit and lack of nutritious knowledge (Wang; Su and Fan, 2016). Research indicates, nowadays college students are not having enough nutritious conscientious, not attach importance to health, have lots of opportunities for eating outside, and poor quality of diet and nutrition (Chen and Yen, 2015). A great portion of students have unreasonable protein taking, deficient nutrition knowledge, not eating breakfast, and irregular diet habits. Hence, there is a need to increase college students nutrition knowledge, make them take a reasonable and balance diet (Liu et al., 2013). We have to strengthen college student education and promote healthful diet( $\mathrm{Li}$, 2018 ; Wang, 2016).

Health consciousness is raising, healthy diet has being valued highly, People are paying more attention on low fat, low sodium and low cholesterol foods, and eating seasonal food with its original flavor and nutrition(Yang et al., 2015). "Diet education" is an education of diet activities (Yan et al., 2015). Diet activities are activities of taking food nutrition. It is a part of life style, not only teaching nutritious knowledge and wishing to change nutrition and health attitude, but other factors need to be considered (Fu and Jien, 2009). A lot of experts agreed that diet education is helpful for Taiwanese's nutrition knowledge, diet habit, sense of food safety and social development (Yan and Zeng, 2014).They suggested that college education should include correct nutritious knowledge, and thus improve students' diet activities for better health conditions (Chen et al., 2016).

\section{Research Methods and Process}

\subsection{Data Collection}

Target of this research is based on college students in Tainan, Taiwan,201. A college was chosen by random. Questionnaires were distributed by the researcher between April 8-22, 2017. Total number of questionnaires distributed were 172, number of valid collected were 98 , collected ratio $56.9 \%$. The distribution of the people that participated in the final sample were: 40 males, 58 females; 74 people, were staying in dormitory.

\subsection{Research Tool}

Information collection of this research was done through questionnaire survey. The questionnaire was "Diet habit in campus survey". Based on the research purpose, the author 
observed kinds of food served around Tainan city campuses, interviewed related persons around campuses (such as students, teachers, administrative staff, and visitors), reviewed related webpages and documents, then developed the questionnaire. Contents of the questionnaire includes: basic information, diet habit, and most favorite foods. Basic information and diet habit are single choice, most favorite foods are multiple choices.

\subsection{Data Analysis}

Collected information was analyzed through SPSS (22.0version), descriptive statistics includes: ratio, average, and standard deviation.

\section{Result and Discussion}

\subsection{Diet Habit of College Students}

Sample information shows, college students' acceptable expenses within the campus for a meal is NTD73.83. Diet with other/s is the highest ratio (45 person, 45.9\%), then occasional with other/s (39 person, 39.8\%), the least is eating alone (14 person, 14.3\%). Considerations of their choices are: highest ratio for "taste" and "price",38 persons (38.8\%) and 25 persons $(25.5 \%)$ respectively; then "habit" and "convenience", 14\% (14.3persons) and 13\%(13.3persons) respectively; the least are "hygiene" and "service", only 8 persons $(5.2 \%)$ chose hygiene, and no one chose service. Frequencies of buying late night snacks are: most of them buying 1-2 times (62 persons, 63.3\%) a week, 24 persons (24.5\%) 3-4 times, as shown in Table 1. Overall statistics shows: diet habit for most students is going with other/s, taste and price are key factors that affect their diet choices. This indicates that most of them are eating around the campus; taste, price and convenience are their major considerations; and hygiene is not important for them. Most students ate late night snacks 1-2 times a week. Such diet habit is a worrying scenario. 
Table 1. Students diet habit and consideration factor $(n=98)$

\begin{tabular}{|llll|}
\hline \multicolumn{1}{|c}{ Variable } & & $\mathrm{n}$ & Ratio \\
\hline Diet within the campus & Alone & 14 & 14.3 \\
& Go with other/s & 45 & 45.9 \\
& Uncertain & 39 & 39.8 \\
Major diet consideration & Habit & 14 & 14.3 \\
& Taste & 38 & 38.8 \\
& Convenience & 13 & 13.3 \\
& Price & 25 & 25.5 \\
& Hygiene & 8 & 8.2 \\
& Service & 0 & 0.0 \\
\hline
\end{tabular}

\subsection{Most Favorite Foods of College Students}

In order to probe students' favorite foods, this research sorted out 68 kinds of foods for students multiple choices. The result shows, top ten students favorite foods in order are: small steamed bun (soup dumpling), Taiwan fries (yan shu ji), sushi, omelet rice (dan bao fan), light fried chicken cutlet, deep fried chicken cutlet, steak, smelly tofu, grilled chicken, and spaghetti (Table 2). It shows, features of students' favorite foods are snacks, fried, and flour related high calorific foods. 
Table 2. Ranks of favorite foods of college students

\begin{tabular}{|l|lll|}
\hline \multicolumn{1}{|c}{ Food } & $\mathrm{n}$ & $\%$ & ran \\
\hline Small steamed bun & 64 & 66 & 1 \\
\hline Taiwan fries & 61 & 62.9 & 2 \\
\hline Sushi & 59 & 60.8 & 3 \\
Omelet rice & 58 & 59.8 & 4 \\
Light fried chicken cutlet & 58 & 59.8 & 4 \\
\hline Deep fried chicken cutlet & 56 & 57.7 & 6 \\
Steak & 53 & 54.6 & 7 \\
Smelly tofu & 46 & 47.4 & 8 \\
Grilled chicken & 51 & 52.6 & 9 \\
Spaghetti & 51 & 52.6 & 9 \\
\hline
\end{tabular}

Further analysis of food ingredients and nutrition shows in Table 3 and Table 4. This table indicates: top ten college students favorite foods are available from food stands around campuses. These foods are processed and sold by roadsides. Their hygiene environment are not good, cooking facilities are simple, and food qualities are not secured (Zhou, 2010). Meanwhile, these foods ingredients are high fat, high calorie, and less cellulose. Except sushi, fats of all these foods are exceeding $30 \%$ of "daily diet suggestions" published by National Health Bureau of Ministry of Health and Welfare, R.O.C.(Taiwan) (Health Promotion Administration ,Ministry of Health and Welfare, 2018). Most students are not reaching suggested ratio of the three nutrition taking: protein 10-20\%, lipid 20-30\%, carbohydrate 50-60\%. Also, main ingredients of Table 4 are lacking vegetables. Only 27 students $(27.6 \%)$ in this research chose vegetable salads. This reveals that most college students' diet are imbalanced, short of vegetables, and less cellulose taking. They are harmful to health. 
Table 3. Favorite foods ingredients of college students

\begin{tabular}{|llc|}
\hline \multicolumn{1}{|c}{ Type of food } & \multicolumn{1}{c|}{ Main ingredients } & Weight/per serve \\
Small steamed bun & Flour, minced pork, scallion & $105 \mathrm{~g}$ \\
Taiwan fries & Chicken breast, flour, fried oil & $200 \mathrm{~g}$ \\
Sushi & Rice, vinegar, sugar & $125 \mathrm{~g}$ \\
Omelet rice & Egg, rice & $400 \mathrm{~g}$ \\
Light fried chicken cutlet & Chicken, fried oil & $200 \mathrm{~g}$ \\
Deep fried chicken cutlet & Chicken breast, fried oil & $200 \mathrm{~g}$ \\
Steak & Beef and noodles & $170 \mathrm{~g} \mathrm{add} 124 \mathrm{~g}$ \\
Smelly tofu & Tofu, fried oil & $150 \mathrm{~g}$ \\
Grilled chicken & Chicken, sauce & $85 \mathrm{~g}$ \\
spaghetti & Sauce, spaghetti & $248 \mathrm{~g}$ \\
\hline
\end{tabular}

Table 4. Favorite foods nutrition analysis of college students

\begin{tabular}{|lccccc|}
\hline Type of food & fat & carbonhydrate & protein & cellulose & calorie \\
Small steamed bun & $43 \%$ & $37 \%$ & $20 \%$ & $3.7 \mathrm{~g}$ & 250 \\
Taiwan fries & $65 \%$ & $10 \%$ & $25 \%$ & $0.6 \mathrm{~g}$ & 610 \\
Sushi & $3 \%$ & $85 \%$ & $12 \%$ & $1.1 \mathrm{~g}$ & 189 \\
Omelet rice & $35 \%$ & $49 \%$ & $16 \%$ & $2.8 \mathrm{~g}$ & 380 \\
Light fried chicken cutlet & $67 \%$ & $9 \%$ & $23 \%$ & $0.6 \mathrm{~g}$ & 541 \\
Deep fried chicken cutlet & $44 \%$ & $29 \%$ & $27 \%$ & $1.2 \mathrm{~g}$ & 470 \\
Steak(beef) & $55 \%$ & $0 \%$ & $45 \%$ & $0 \mathrm{~g}$ & 214 \\
$\quad$ (noodle) & $18 \%$ & $23 \%$ & $10 \%$ & $5.2 \mathrm{~g}$ & 170 \\
Smelly tofu & $52 \%$ & $10 \%$ & $38 \%$ & $1.8 \mathrm{~g}$ & 189 \\
Grilled chicken & $53 \%$ & $0 \%$ & $47 \%$ & $0 \mathrm{~g}$ & 201 \\
Spaghetti & $33 \%$ & $47 \%$ & $20 \%$ & $5.2 \mathrm{~g}$ & 350 \\
\hline
\end{tabular}




\section{Conclusion}

Results of this research are: students' acceptable average dinning expenses is NTD 73.83 per person per meal; highest dinning habit is going with other/s, least ratio is dinning alone; most of them are eating at cafeteria; major choice considerations are taste and price. $63 \%$ of students take late night snacks at least once a week. Notably, their diet requirements are merely convenience, likeness, cheap; and not care about hygiene and service. This research also found that top ten favorite foods for college students are available around campuses. These foods are cooked and sold by the roadsides.

Food safety is a potential concern. College students like to eat Taiwan fries, light fried chicken, deep fried chicken, steak, smelly tofu, grilled chicken and spaghetti. These are high fat, high calorie foods, which are having adverse impact toward students' health. In spite of these facts, this research discovered that these favorite foods are not complying with daily diet norms. The three nutrition taking ratio for college students are following far behind "daily diet suggestion" (protein 10-20\%, lipid 20-30\%, carbohydrate 50-60\%), and short of vegetables and cellulose taking. Researches indicated repeatedly that, never ignore taking enough vegetables and fruits; it keeps healthy (Health Promotion Administration ,Ministry of Health and Welfare, 2018); Nutrition and hygiene are key factors for college students health. Unfortunately, most college students are not paying attention to them. Therefore, school cafeterias are bearing responsibilities for solving these problems (Zeng, 2016).

Flourishing of campuses vicinity dinning and potential problems should be improved, and provide a safe and hygienic dinning environment for college students (Peng et al., 2017). After all, we cannot simply count on individual behavior change. Social environment need to be changed (Liu and Yang, 2010). Since convenience is a major consideration for college students dinning, we suggest Taiwan government take it seriously.

\section{References}

Chih, Y. C., Su, S. J., Lin, K. H., Tang, K. S. (2016). An exploration of fundamental and essential healthcare knowledge and skills for college students. Fooyin Journal of General Education, (3), 75-91.

Chen, P. Y., Lai, Y. M., Chen, R. Y., Sun, J. L. (2016). The relationships between nutritional knowledge, dietary behavior and health status among university students. Journal of Health and Architecture, 3(3), 52-60. 
Chen, M. L., Yen, C. Y. (2015). A study of students' perceptions of health consciousness, health cognitions and diet behaviors in case of four universities in central Taiwan. Hung kuang Journal, (76), 111-122.

Fu, A. H., Jien, J. J. (2009). The impact of college students' attributes on nutrition knowledge, dietary attitudes, and dietary practices in Taiwan. Nutritional Sciences Journal, 34(4), 142-154.

Hang, C. M., Yang, H. C., Hung, H. C., Chen, L. M., Hsu, T. L., Lin, W. (2009). The nutrition education and dietary environment in schools of Taiwan (IV): The college. Nutritional Sciences Journal, 34(3), 76-84.

Health Promotion Administration, Ministry of Health and Welfare. ( 2018). Daily Dietary Guidebook, Retrieved May 22, 2011, from https://www.hpa.gov.tw/Pages/EBook.aspx?nodeid=1208.

Lee, W. I.(2013). The Impact of Price Perception, Product Quality and Service Quality on Behavioral Intention for Brunch Stores. Master's thesis of Nantai University of Science and Technology.

Li, C.Y. (2018). Investigation on nutritional knowledge, attitude and behavior of students in higher vocational colleges in changzhou and evaluation of dietary status. Chinese Journal of Preventive Medicine, 36(3), 320-323.

Li, M. F. (2013). Study on the Factors Affecting Life and Eating Habits of Adolescents with Abnormal Body Mass Index and Weight Control Problems. Master's thesis of National Taiwan Ocean University.

Liu, J., Li, L. F., Xiao, Q. H. (2013). The influence of nutrition knowledge attitude behavior (KAP) on college students' dietary nutrition. Food and Machinery, 29(3), 104.

Liu, X. K., Yang, S. C. (2010). Diet and lifestyle strategies to reduce the risk of cardiovascular disease. International Journal of Advanced Information Technologies (IJAIT), 4(1), 53-67.

Luo, L. N., Su, W. T., Yang, S. T. (2017). The influence of unhealthy living habits on college students' physical health. Contemporary Sports Technology, 7(20), 18-18.

Luo, X. Y., Lai, G. J., He, Q. Y., Huang, S. Y. (2012). Nutrient analysis and dietary recommendations for breakfast. Journal of Taiwan Nutrition Society, 37(4), 147-154.

Luo, Y. F., Yang, S. Q., Jiang, J. X., Lu, J. M. (2018). Construction of self-report scale of college students' food literacy and its relationship with beverage behavior. Taiwan Journal of Public Health, 37(4), 407-419.

Peng, W. Y., Li, K., Deng, Q. Q., Luo, X. (2017). Investigation and analysis of food safety hazards around colleges and universities -- taking Jishou University as an example. Food Safety Guide, (27), 118.

Shen, P., Ma, G. S., Zhou, P. G., Liu, Y. P. (2015). Try these nutrition improvement programs for different breakfast eaters. Self-care, (4), 30-31.

Su, X. Y., Fan, J. (2016). Analysis of nutrition and health status of college students in higher vocational colleges. Inner Mongolia Science, Technology and Economy, (15), 33-34. 
Wang, Q. (2016). Investigation on dietary nutrition of college students in changzhi city. Journal of Changzhi University, 33(2), 92-95.

Yan, J. X., Zeng, Q. H. (2014). Study on the construction of food and breeding connotation index. Agricultural Extension, 27-50.

Yan, J. X., Zeng, Y. L., Zhang, W. Q., Chen, M. F., Xie, Y. T. (2015). Research on the promotion strategy of food and agriculture education in China. Agricultural Extension Wenhui, 69-86.

Yang, A. S., Lai Y. Y., Ou T. T. (2015). A study on the satisfaction and loyalty of health perception in vegetarian restaurants - a case study of Taichung Herb Garden Restaurant. International Symposium on Educational Innovation: Educational Development and Industry-academic Cooperation, 1-25.

Zeng, X. L. (2016). A brief discussion on the diet hygiene management of college student canteens. Global Markets, (29), 94-94.

Zhou, S. Q. (2010). The present situation and management countermeasures of food sanitation and safety around the school. Chinese Journal of School Doctor, (2), 141-142. 